TEIPfallis.pdf

$6 / 10 / 07$

\title{
Toward an Epistemology of Intellectual Property
}

\author{
Don Fallis \\ School of Information Resources \\ University of Arizona \\ fallis@email.arizona.edu
}

Journal of Information Ethics, 16, 2, (2007): 34-51.

http://dx.doi.org/doi:10.3172/JIE.16.2.34

The original publication is available at http://mcfarland.metapress.com. 


\title{
Toward an Epistemology of Intellectual Property
}

\begin{abstract}
An important issue for information ethics is how much control people should have over the dissemination of information that they have created. Since intellectual property policies have an impact on our welfare primarily because they have a huge impact on our ability to acquire knowledge, there is an important role for epistemology in resolving this issue. This paper discusses the various ways in which intellectual property policies can impact knowledge acquisition both positively and negatively. In particular, it looks at how intellectual property policies can affect the amount of information that people create, the quality of that information, the accessibility of that information, the diversity of that information, and the locatability of that information.
\end{abstract}

\section{Information Management Policies and Epistemology}

Information ethics is essentially concerned with how we ought to manage information and information technology. Thus, a major task for information ethicists is to evaluate policies for managing information from an ethical perspective. For example, should there be any restrictions on who can disseminate certain types of information? In particular, how much control should people have over the dissemination of information about themselves? Also, how much control should people have over the dissemination of information that they have created? ${ }^{1}$

Toward this end, information ethicists typically try to determine the likely consequences of such information management policies. There are, of course, information ethicists who give non-consequentialist evaluations of information management policies. For example, Adam Moore (2001) and Richard Spinello (2003) defend a Lockean theory of intellectual property. However, the actual consequences of policies are typically relevant for even such non-consequentialist evaluations (cf. Fallis 2004a, 102). For example, according to John Locke (1689), an individual can only acquire property rights in unappropriated items if there is "enough and as good left in common for others." And whether this Lockean proviso is satisfied depends on the actual consequences.

In most cases, information ethicists look directly at the consequences that information management policies have on people's welfare. However, information management policies have an impact on people's welfare primarily because they have a huge impact on people's ability to acquire knowledge. As a result, there is an important role for epistemologists in the evaluation of information management policies (cf. Goldman 1999, 161-188, Fallis 2004a). ${ }^{2}$

\footnotetext{
${ }^{1}$ In addition to questions about who can disseminate information, there are also questions about who can access information (cf. Fallis 2004a).

${ }^{2}$ It should be noted that, while greater information access and more knowledge acquisition usually lead to better consequences all things considered, they do not always do so (cf. Fallis 2007, 35-39). For example, it would be better all things considered if terrorists did not acquire knowledge about how to build bombs.
} 
In fact, this is a fairly important application of epistemology. One of the main ways that people acquire knowledge is from other people (cf. Hume 1748, 74). And, in particular, we often acquire knowledge by accessing recorded information of various sorts (books, newspapers, journals, websites, databases, etc.). Thus, information management policies can have a huge impact on the knowledge that we can acquire because they have a profound effect on the recorded information that we can access. ${ }^{3}$

\section{Intellectual Property Policies}

This paper focuses specifically on information management policies that dictate how much control people have over the dissemination of information that they have created. Such intellectual property policies have existed for thousands of years. For example, ancient Greek chefs apparently had exclusive rights to their recipes (cf. Moore 2001, 910). But the question of exactly what intellectual property policies to adopt has recently become much more pressing. Advances in information technology (e.g., peer-to-peer networking) have made it much easier for people to disseminate information that other people have created. In response, legislators have given people more legal control over the dissemination of information that they have created (e.g., with the Digital Millennium Copyright Act and the Copyright Term Extension Act). ${ }^{4}$ This paper discusses the impact (both positive and negative) that such intellectual property policies can have on people's ability to acquire knowledge. ${ }^{5}$

Intellectual property policies in the United States include copyright law, patent law, and trade secret law (cf. Moore 2001, 15-23). ${ }^{6}$ For example, copyright law gives authors the exclusive right to disseminate copies of their works and to produce derivative works. Patent law gives inventors the exclusive right to manufacture a device or to use a process. ${ }^{7}$ Trade secret law gives businesses control over the dissemination of information

${ }^{3}$ Epistemology has traditionally focused on the epistemic consequences of policies that individuals might adopt (e.g., about how to gather and evaluate evidence). But, as Goldman $(1999,4)$ points out, epistemology can also look at the epistemic consequences of broader social policies.

${ }^{4}$ In addition to such legislative responses to this situation, there have been many technological and economic responses as well (cf. Shapiro and Varian 1999, 83-102). ${ }^{5}$ Only a few writers (e.g., Warner 1993, 307, Dorbolo 1997, Goldman 1999, 181-182, Fallis 2004a, 105-109) have explicitly discussed the connection between intellectual property and epistemology. And they have done so only briefly.

${ }^{6}$ Trademark law is another intellectual property policy that can have an impact on knowledge acquisition. For example, I can acquire knowledge about the quality of your product or service if other people are not allowed to use your trademark (cf. Posner 2007, 68-69). But this paper focuses primarily on those cases where people can acquire knowledge directly from the content of the intellectual property.

${ }^{7}$ Strictly speaking, patent law gives people control over the use, rather than over the dissemination, of information that they have created. In fact, patents require inventors to give up control over the dissemination of the information that they have created. However, control over the use of information can certainly have an impact on the 
that gives them a competitive advantage and that they have taken reasonable precautions to keep secret.

But there are also intellectual property policies that are not codified in the law. For example, there is no law against plagiarism (cf. Posner 2007, 34). ${ }^{8}$ However, most people think that only the author of a work has the moral right to claim to be the author of that work. As a result, there are usually serious consequences (even if not legal penalties) for violating this right. ${ }^{9}$

This paper looks at the epistemic consequences of these various intellectual property policies. But it does not always goes into great detail about the specifics of the policies. The epistemic consequences of a policy largely depend on the degree of control people have over the dissemination of information that they have created. Thus, I frequently just talk about strong intellectual property policies (i.e., those that give people a lot of control) and weak intellectual property policies (i.e., those that that do not). ${ }^{10}$

\section{The Impact on the Creation of Information}

The most obvious respect in which intellectual property polices can impact knowledge acquisition is by giving people an incentive to create information (cf. Hettinger 1989, 4748, Goldman 1999, 181-182). This motivational role is clearly the point of intellectual property law in the United States. According to the United States Constitution (Article I, Section 8), the goal of intellectual property law is to "promote the progress of science and useful arts."

Here is how this plays out in the case of copyright law: ${ }^{11}$ Without the exclusive right to disseminate copies of their works, it would be difficult for authors to make a profit selling their works. For example, they would potentially be in competition with other people who could also sell copies, but who did not have to create these works in the first place. But with this exclusive right, authors essentially have a monopoly on their works. Thus, they often can make a profit selling their works. And this potential profit arguably motivates them to create information. ${ }^{12}$

dissemination of this information. For example, I will be less likely to acquire knowledge about how to manufacture a device (and less likely to try to discover how to improve the device) if I am not allowed to actually manufacture it.

${ }^{8}$ Many instances of plagiarism are illegal. But this is only because they also involve copyright infringement.

${ }^{9}$ Similarly, the "Protocols for Native American Archival Materials" (http://www2.nau.edu/libnap-p/) are an attempt to spell out the rights of indigenous peoples to their cultural information that libraries and archives ought to respect (even if they are not legally required to do so).

${ }^{10}$ In a similar vein, Landes and Posner $(1989,334)$ use a single index to measure the degree of copyright protection that a particular policy provides.

${ }^{11}$ There is an analogous story for other intellectual property policies, such as patent law.

${ }^{12}$ In addition to motivating them to create intellectual property, such profit can bankroll future creative projects for successful authors. 
Discussions of the motivational role of intellectual property policies tend to focus on the profit motive. But many people are also motivated to create new information simply because they want to get credit for having created it (cf. Anderson 2006, 73-75). In particular, scientists are typically more interested in getting credit for their discoveries than in profiting from their discoveries (cf. Goldman 1999, 260). But intellectual property policies can also help to insure that people have this motivation to create new information. For example, without the exclusive right to claim authorship of their works (i.e., without rules against plagiarism), it would more difficult for people to get credit for their intellectual work. Thus, people would have less incentive to engage in creative projects. In addition, the exclusive right to disseminate copies of their works allows authors to make sure that their names are on their works.

Admittedly, it is not just profit and credit that motivates people to create new information. For example, many people consider engaging in creative projects to be intrinsically valuable. And, even when people are motivated by profit, there are other ways that they could profit even if they did not have control over the dissemination of information that they created. For example, creative projects could be funded by government grants or by philanthropy (cf. Hettinger 1989, 49). But, even if control over dissemination is not the only way to motivate people to create information, it is a very common way to motivate people. Thus, it is important to ask about the epistemic consequences of people having such control.

\section{The Downside:}

While intellectual property policies can promote the creation of new information, giving people control over the dissemination of information that they have created also has a downside. Such control can easily impede the creation of new information as well. In particular, it potentially restricts further innovation (cf. Landes and Posner 1989, 332)

Most intellectual work builds on previous intellectual work (cf. Hettinger 1989, 38, Mann 1998, 82). For example, as Sir Isaac Newton famously said about his scientific discoveries, "if I have seen further it is by standing on ye shoulders of Giants." But if the creators of the previous intellectual work have an exclusive right to produce derivative works, there is less motivation for other people to build on their work. In fact, they are deterred from doing so. ${ }^{13}$ Thus, it is an empirical question what the net effect of a strong intellectual property policy will be on the amount of new information that is created (and on the speed with which it is created).

People can voluntarily give up the control that leads to this downside. For example, the Creative Commons organization helps people to craft weaker copyright agreements for their intellectual property (cf. Anderson 2006, 75). In addition, there are many Open

${ }^{13}$ Such restrictions on further innovation are not the only way that intellectual property policies can impede the creation of new information. For example, intellectual property policies that protect indigenous knowledge can impede anthropological research (cf. Brown 1998, 203-204). 
Access archives, such at the Digital Library of Information Science and Technology (http://dlist.sir.arizona.edu), that provide free access to scholarly and educational materials. But regardless of whether people can give up this control, it is still important to determine the epistemic consequences of people having the control that strong intellectual property policies give them in the first place. ${ }^{14}$

We cannot eliminate restrictions on further innovation simply by eliminating these intellectual property policies. Admittedly, if we eliminated these policies, people would not be deterred from producing derivative works based on information created by others. But everyone would have less motivation to produce original works or derivative works going into the future. In fact, we might not have this information to build on in the first place unless the creator expected to have control over the dissemination of the information.

But in order to reduce restrictions on further innovation without also eliminating the motivation to create new information, legislators have put some limitations on the exclusive rights of creators. For example, the control that people have over the dissemination of information that they have created typically only lasts for a limited period of time. Such control still allows authors to make a profit selling their works. But, after a certain period of time, anyone is free to produce derivative works. ${ }^{15}$ Also, in the United States, an individual can only copyright particular expressions of ideas. An author cannot copyright the ideas themselves (cf. Moore 2001, 17). Similarly, an inventor cannot patent scientific facts. Such limitations make it somewhat less likely that further innovation will impeded.

However, the United States Congress continues to extend the period of time that people have control over their intellectual works (e.g., with the Copyright Term Extension Act). Also, the United States Patent Office is now coming very close to issuing patents for basic scientific facts (cf. Andrews et al. 2006). In fact, current intellectual property law may even make it illegal to disseminate certain mathematical facts: Creators often use sophisticated encryption algorithms to keep other people from copying their intellectual property. The Digital Millennium Copyright Act (DMCA) makes it illegal to circumvent these encryption algorithms by using decryption algorithms. In addition, the DMCA makes it illegal to distribute these decryption algorithms. However, such a decryption algorithm can easily be encoded as a very large prime number (cf. Caldwell 2007). This suggests that it is illegal to disseminate the information that this number is prime (since it is illegal to disseminate the number itself). ${ }^{16}$

\section{Only Finitely Many Ideas Left Over:}

${ }^{14}$ Of course, we could also evaluate the epistemic consequences of the Creative Commons itself. Since it simply gives creators the option to give up some control over their intellectual property, it would seem to primarily have epistemic benefits.

${ }^{15}$ Of course, further innovation may still be slowed down.

${ }^{16}$ Since these numbers are so large, the fact that they are prime is reasonably interesting (cf. Caldwell 2007). 
But it might be suggested on theoretical grounds that such restrictions on further innovation do not necessarily lead to a net loss in knowledge acquisition. For example, Moore $(2001,114)$ and Spinello $(2003,10)$ essentially claim that the Lockean proviso is always satisfied when it comes to intellectual property. That is, when someone takes ownership of an idea, "enough and as good" is always left for others. As Spinello puts it, "there is one less unappropriated and unimagined idea for inventors to conjure up, what does that matter when the sum of those ideas is virtually infinite?" Thus, while strong intellectual property policies might preclude me from building on the ideas of others, I would not be precluded from developing equally valuable ideas of my own because there are infinitely many ideas left out there.

However, it is not clear that there really are infinitely many valuable ideas left out there at any given time. Since most intellectual work builds on previous intellectual work, the number of valuable ideas that people might come up with at any given time is actually quite limited. For example, as Charles Fort $(1923,530)$ pointed out, "the secret of the steam engine could not, to the lowliest of intellects, or to supposititiously highest of intellects, more than adumbratively reveal itself until came the time for its co-ordination with the other phenomena and the requirements of the Industrial Age." In other words, until all sorts of knowledge was in place, no one was going to come up with the idea of the steam engine.

\section{The Impact on the Quality of Information}

In the previous section, I argued that intellectual property policies can have a significant impact on the creation of information. But, as epistemologists, we are not just interested in information per se. We are interested in information that will lead to knowledge acquisition. That is, we are interested in information that will allow people to acquire justified, true beliefs. ${ }^{17}$

In order for people to acquire knowledge from information, that information typically must meet certain quality standards (cf. Miller 1996). For example, information needs to be comprehensible in order for people to acquire beliefs from the content. Also, information typically needs to be accurate and complete in order for people to acquire true beliefs. ${ }^{18}$ Finally, information typically needs to be verifiable in order for people to acquire justified beliefs (cf. Fallis 2004b, 476-477).

In addition to acquiring beliefs that are true and justified, we typically want to acquire knowledge of significant matters that are of interest to us (cf. Paterson 1979, 95,

\footnotetext{
${ }^{17}$ There seem to be other conditions on knowledge beyond truth and justification (cf. Gettier 1963). But most epistemologists agree that knowledge must meet at least these conditions.

${ }^{18}$ Copyright law gives authors control over their fictional works as well as their nonfiction works. And it is certainly possible to acquire knowledge by reading fiction even though it describes a lot of things that never happened (cf. Meiklejohn 1981, 256). But this paper focuses primarily on those cases where people can acquire knowledge about the world directly from what the information says about the world.
} 
Goldman 1999, 88-89). And this requires information about significant matters that are of interest to us.

If information does not meet these quality standards, it might actually be epistemically better if such information were not available (cf. Goldman 1999, 212). For example, inaccurate and incomplete information can lead people to acquire false beliefs (cf. Fallis $2004 b, 465)$. In this section, I argue that intellectual property policies can have an impact (usually positive) on whether information meets these standards. ${ }^{19}$

\section{Information Stewardship:}

Strong intellectual property policies essentially give people "ownership" of the information that they have created. As a result, they can potentially make a profit as the exclusive source for this information. And they can presumably make more money if they have a quality product. For example, it is only really useful to hold patent for a device if the device actually works. Thus, creators are presumably motivated to make sure that their information meets the aforementioned quality standards. ${ }^{20}$

In particular, strong intellectual property policies seem to motivate people to create information on more significant matters: An author can still sell copies of the book that she has written even if she do not have an exclusive right to do so. And, even if other people are allowed to sell copies of the book, the author has a small advantage because she is likely to be the first one into the market. But if authors can only count on this small advantage, it will arguably lead to the publication of more trivial and ephemeral works (cf. Landes and Posner 1989, 332). In fact, this is precisely what happened when intellectual property laws were eliminated following the French Revolution (cf. Mann 1998, 74).

Giving people control over the dissemination of their intellectual work is just one example of promoting information stewardship (cf. English 1999, 401-419). In order for information to meet these quality standards, there usually needs to be someone who takes responsibility for this happening. There are a number of reasons why someone might be motivated take on this sort of responsibility. For example, someone might be employed to insure the accuracy of a corporation's data or someone might volunteer to insure the quality of a non-profit organization's website. But if someone can make a profit because she can control the dissemination of information that she has created, she will have greater motivation to insure the quality of that information.

Finally, intellectual property policies can also have an impact on how easy it is for people to determine whether a piece of information is accurate. As David Hume $(1748,75)$

${ }^{19}$ Library and information scientists often focus on how the critical thinking skills of the information seeker affect knowledge acquisition, but the quality of the information itself also has a huge impact (cf. Fallis 2004b, 477-478).

${ }^{20}$ In order to acquire knowledge, we also need information that tells us something that we do not already know (cf. Goldman 1999, 105). The originality requirement on copyrights and patents arguably support this epistemic objective. 
points out, knowing about the source of the information can help determine whether the information itself is accurate (cf. Fallis 2004b, 469-470). However, plagiarism hides the actual source of the information. In addition, plagiarism makes it more difficult for readers to verify information by checking documents that refer to the original source (cf. Snapper 1999, 129). Thus, rules against plagiarism increase the verifiability of information. ${ }^{21}$

\section{The Downside:}

It has been suggested that financial incentives to create new information sometimes lead to the creation of lower quality information. For example, Esther Dyson claims that "we could have more good things and be inundated by fewer bad ones" if there were no copyright, because "there will be less incentive for trashy stuff that is only marketed for money" (quoted in Mann 1998, 72). Also, in addition to giving them a motivation to insure the quality of their intellectual property, such financial incentives give creators a motivation to protect their intellectual property. And this can actually lead creators to lower the quality of their intellectual property in some cases. For example, mapmakers introduce small inaccuracies in order to be able to prove that someone has copied their work (cf. Monmonier 1991, 49-51). Also, compilers of tables of logarithms used to introduce small errors for the very same reason (cf. Dembski 2004, 314-315). But it still seems safe to conclude that strong intellectual property policies usually lead to the creation of higher quality information. ${ }^{22}$

\section{The Impact on the Accessibility of Information}

Of course, quality information cannot help people to acquire knowledge unless they actually have access to it. Intellectual property policies often directly insure the accessibility of information. For example, a author can only profit from her intellectual work by making it accessible to people (for a price). In fact, in order to get copyright or patent protection in the United States, creators are required to publicly disclose their intellectual property. Such disclosure clearly has important epistemic benefits (cf. Hettinger 1989, 36).

Furthermore, there are several other respects in which intellectual property policies can have a positive impact on accessibility. ${ }^{23}$ In particular, there are many instances in which people may decide to keep information to themselves unless they have control over how the information is disseminated. For example, unless people can get credit for their discoveries, it may be most advantageous for them to continue to make discoveries, but to

\footnotetext{
${ }^{21}$ Rules against plagiarism also insure that readers do not acquire a false belief about who the source is. Of course, if students plagiarize from accurate sources, it might lead to more true beliefs than if they actually came up with their own ideas.

${ }^{22}$ It has been suggested that the proposed Collections of Information Antipiracy Act would "make reporters and scientists reluctant to cite facts" (Mann 1998, 79). This would certainly decrease the verifiability of information.

${ }^{23}$ In addition, information stewardship may involve an obligation to ensure accessibility as well as quality (cf. Sax 2000, 112).
} 
keep these discoveries secret. ${ }^{24}$ During the Renaissance, mathematicians often gained their reputation by winning mathematical contests rather than by publishing results (cf. Dunham 1990, 134-135). As a result, keeping their discoveries secret was actually the best way to get credit for their discoveries. Thus, strong intellectual property policies (e.g., rules against plagiarism and copyright law) can increase the accessibility of information by helping to insure that people will get credit for their discoveries.

In addition, trade secret law can have a similar positive impact on the accessibility of information. On the face of it, it might seem that such a law would simply block the dissemination of information and knowledge acquisition (cf. Hettinger 1989, 36). But in many cases, people would like to share their information with a limited group of people (e.g., their employees), but they do not want to share with everyone in the world. Such people might not share their information with anyone at all unless they are sure that it will only go to the intended audience. As Lynn Paine $(1991,253)$ puts it, "if we could not select our audience, that is, if the choice were only between keeping ideas to ourselves and sharing them with the world at large, many ideas would remain unexpressed. ${ }^{, 25}$ Thus, trade secret law can increase the accessibility of information by assuring that it will not go any farther than intended. ${ }^{26}$

Trade secret law is essentially a way to protect the privacy of a corporation. And the epistemic benefits of such privacy protection can be even greater if the corporation in question is in the business of providing access to information. For example, the public may have access to more information overall if only the journalists working at a newspaper have access to the identity of confidential sources.

\section{The Downside:}

However, strong intellectual property policies can also limit accessibility of information. If she has a monopoly on the information that she has created, a creator can charge people quite a bit to access this information. In particular, she can charge much more than the marginal cost of providing people with access to this information. ${ }^{27}$ As a result, many people who would benefit from having access to this information may not be able to afford to purchase such access.

${ }^{24}$ Since other people may end up independently making the same discovery (e.g., if it is steam engine time), such secrecy will not necessarily stop the dissemination of this information, but it will certainly slow it down.

${ }^{25}$ It would certainly be epistemically better if everyone had access to the information. But, without trade secret law, even fewer people are likely to have access to the information.

${ }^{26}$ Trade secret law might facilitate the limited dissemination of cultural information as well as business information. For example, according to Stevenson $(2000,1174)$, "protecting their medicinal knowledge as a trade secret gives indigenous communities the option to share this knowledge while at the same time avoiding further exploitation."

${ }^{27}$ Even though she has a monopoly on the information that she has created, a creator cannot charge whatever she wants. The demand for any particular information good may be fairly elastic (e.g., because other information goods are good substitutes). 
This is a waste (cf. Hettinger 1989, 35). Unlike tangible goods (e.g., cars and televisions), information goods (e.g., books and newspapers) are non-rival. That is, providing more people with access to an information good does not interfere with the people who already have access. In particular, some people will be epistemically better off and no one will be epistemically worse off. ${ }^{28}$ As Thomas Jefferson $(1813,630)$ famously put it, "he who receives an idea from me, receives instruction himself without lessening mine; as he who lights his taper at mine, receives light without darkening me."

In addition to restricting access to information that creators are currently selling, strong intellectual property policies can restrict access to other information that people could acquire knowledge from. For example, the Copyright Term Extension Act has greatly increased the number of so-called orphan works (cf. Carlson 2005). These are works under copyright that are so old that it is difficult to determine who holds the copyright. As a result, it is very difficult for people to get permission to use these works in some way (e.g., in library digitization projects). And people may reasonably worry that someone will "crawl out of the woodwork" and sue them for copyright infringement if they go ahead without permission. Thus, this particular intellectual property policy may deter people from engaging in projects to preserve and to provide access to such works.

But we face the same sort of dilemma that we faced with restrictions on further innovation. We cannot eliminate this waste simply by eliminating these intellectual property policies. Admittedly, doing so would increase the accessibility of existing information. But it might also decrease the motivation that people have to create new information going into the future. In fact, we might not have the existing information in the first place unless the creator expected to have control over the dissemination of the information.

But in order to increase the accessibility of information without also eliminating the motivation to create new information, legislators have put some limitations on the exclusive rights of creators (cf. Goldman 1999, 181). For example, once an author sells a copy of her book, she no longer has any control over what happens to that particular copy (cf. Moore 2001, 19). This "first sale" limitation on copyright is what makes it legal for public libraries to buy books and lend them to people. ${ }^{29}$ Thus, as a direct result of this limitation on copyright, people can have access even if they cannot afford to purchase the information for themselves.

\footnotetext{
${ }^{28}$ Of course, someone may be worse off all things considered. This is because knowledge is sometimes a positional good (cf. Hollis 1982). That is, my knowledge can become less valuable (i.e., I can be harmed) when somebody else acquires that knowledge (e.g., about which stocks are likely to increase or decrease in value).

${ }^{29}$ When circulating libraries first opened in the eighteenth century, publishers worried that this loss of control would destroy their business (cf. Shapiro and Varian 1999, 95). But, because libraries promote literacy (another important epistemic benefit of access to information), quite the opposite has happened.
} 
Of course, even with public libraries, strong intellectual property policies still limit the accessibility of information for people who cannot afford to purchase it for themselves. For example, it may take a significant amount of time for them to get a book out of the library (e.g., if someone else has checked it out or if it has to be ordered from another branch). Also, there are typically constraints on how long they can use the book.

\section{Types versus Tokens:}

Again, it is an empirical question what the consequences of any particular intellectual property policy are likely to be with respect to the accessibility of information. But there is also an important theoretical question here (about epistemic values) that epistemologists need to resolve (cf. Fallis 2004a, 109).

There are at least two ways in which intellectual property policies can have an impact on knowledge acquisition. First, because they have an impact on how much new information is created (e.g., on how many new discoveries are made), intellectual property policies can have an effect on how many different pieces of knowledge people can acquire. Second, because they have an impact on how many people have access to information, intellectual property policies can have an effect on how many different people can acquire knowledge from this information.

However, these two epistemic values can easily come into conflict. For example, a strong intellectual property policy might increase the amount of information that is created and, thus, lead to more knowledge types. But a weak intellectual property policy might increase the accessibility of (a smaller amount of) information and, thus, lead to more knowledge tokens. Thus, in evaluating intellectual property policies, it may be important to determine the appropriate tradeoff between the epistemic value of more knowledge types and the epistemic value of more knowledge tokens.

\section{The Impact on the Diversity of Information}

So far, I have focused on the quality and accessibility of individual pieces of information. But we do not just acquire knowledge by taking in individual pieces of information. In particular, we typically access some information in order to evaluate some other information. For example, if we are interested in whether a claim made by one information source is true, we check to see if other information sources corroborate or criticize this claim (cf. Fallis 2004b, 470-471). The fact that we regularly look for such corroborative or critical sources shows that we are interested in the quality of the whole collection as well as in the quality of the individual items in the collection.

In particular, we are especially interested that the collection of information to which we have access represents a diverse set of viewpoints. In fact, we often want to have access to individual items that do not meet certain standards of quality, such as accuracy, precisely in order to insure such diversity (cf. Mill 1859, 36). As John Stuart Mill (1859, 43) points out, we can only be sure that a particular viewpoint is correct if it stands up to 
a variety of competing viewpoints in the marketplace of ideas. ${ }^{30}$ In addition, having access to a diverse set of viewpoints also makes it more likely that the correct viewpoint is available (cf. Mill 1859, 20). In this section, I argue that intellectual property policies can have an impact on the diversity of the information that is available to us.

So, should we really expect strong intellectual property policies to lead to diversity in the information that is available to us? In the past, the answer may have been no. When the fixed costs of publishing a book are fairly high, it is only economically feasible for publishers to sell those few books that a lot of people are going to want to read. However, the answer today seems to be yes. As Chris Anderson (2006) has pointed out, advances in information technology have reduced these fixed costs and made it possible for publishers to make a profit on a long tail of information goods for which there is a fairly low demand. ${ }^{31}$

In addition, it has been suggested that the drive for credit promotes diversity in scientific research (cf. Goldman 1999, 256-257). Not all researchers take the safe paths of inquiry that are most likely to pan out. A few researchers pursue the long shots because the rewards (in terms of recognition) will be greater if they succeed. Thus, strong intellectual property policies (e.g., rules against plagiarism and copyright law) arguably promote this diversity because they help to insure that researchers will actually get this recognition if they succeed.

\section{The Downside:}

But intellectual property policies can also keep people from getting access to certain viewpoints. In fact, intellectual property laws were originally enacted in order for the government to "suppress anything that upset royal sensibilities or ran contrary to their interests" (Mann 1998, 73). And, as Mill (1859, 15-52) has argued, such censorship can certainly interfere with people's ability to acquire knowledge.

Such censorship is not just a thing of the past. Intellectual property policies can still be used to suppress viewpoints. For example, in order to criticize your viewpoint, I often have to repeat some of what you say. In other words, I have to use some of your intellectual property. As a result, intellectual property laws can potentially be used to keep me from criticizing your viewpoint. In fact, the Church of Scientology has effectively used the threat of litigation on these grounds to silence some of its critics (cf. Vaidhyanathan 2002). ${ }^{32}$

\footnotetext{
${ }^{30}$ As Goldman $(1999,212)$ points out, it is not clear how many people will really take a careful look at all sides of an issue. But having all sides available arguably still makes knowledge acquisition more likely.

${ }^{31}$ Of course, there is certainly still strong motivation to produce intellectual works that are similar to works that have already been successful in the marketplace (cf. Posner 2007, 76-78).

${ }^{32}$ The threat of copyright litigation has also been used to try to block the dissemination of unflattering videoclips of the President (cf. Lessig 2004).
} 
But legislators have put some limitations on the exclusive rights of creators that tend to block this sort of de facto censorship without also eliminating the motivation to create new information. For example, the "fair use" limitation on copyright essentially allows people to make various socially beneficial uses of information created by other people without their permission (cf. Moore 2001, 18). This limitation only allows me to use a fairly small amount of your intellectual property. For example, I cannot use so much that the market for your intellectual property will be significantly reduced. ${ }^{33}$ But this amount will typically be enough to allow me to criticize your viewpoint.

As Lawrence Lessig (2004) points out, however, copyright law is sufficiently vague that it can often be very risky for critics to count on a successful fair use defense. In addition, the anti-circumvention provision of the DMCA seriously decreases the effectiveness of the fair use limitation. The fair use limitation may still exist, but it does not do me much good if I cannot even get access to the information for which I have a fair use.

Finally, the fair use limitation does not address all of the ways in which intellectual property policies can keep people from getting access to certain viewpoints. As I argued above, trade secret law can increase the accessibility of information to limited audiences. But trade secret law may have epistemic costs that outweigh this epistemic benefit. For example, when corporations fund research, they frequently only allow results that are favorable to their products to be published (cf. Resnik 2006, 142-143). The unfavorable results are protected by trade secret law. Such bias in the information that is available to people can potentially lead them to acquire false beliefs. ${ }^{34}$

\section{The Impact on the Locatability of Information}

Of course, before people can acquire knowledge from a piece of information, they have to be able to find that information. Since strong intellectual property policies give creators the exclusive right to sell copies of their intellectual property, it seems that such policies would give creators a financial incentive to make their intellectual property very easy to find.

\section{The Downside:}

But strong intellectual property policies can sometimes interfere with people's ability to find the information that they are searching for. The most recent example of how this can happen involves Google's plan to provide a search engine for books as well as for the Internet (cf. Toobin 2007).

The goal of Google Book Search is to provide a search engine for the contents of all books that have ever been published in the same way that the goal of Google Search is to

${ }^{33}$ It is perfectly ok if my criticisms are so devastating the market for your intellectual property is significantly reduced.

${ }^{34}$ Secrecy can also make it more difficult to verify the accuracy of scientific results (cf. Resnik 2006, 142-143). Similarly, if a particular researcher has exclusive access to an archive, others cannot effectively criticize her conclusions (cf. Sax 2000, 110). 
provide a search engine for all of the content that is posted on the Internet. In order to make all these books searchable, Google has to create digital copies of the books (in the same way that it makes copies of websites in order to index them). However, Google does not make entire books accessible to Internet users without the permission of the copyright holder. Instead Google only displays short "snippets" of books. This is intended to be a sufficiently small amount of information that it falls within the fair use limitation on copyright.

Making the universe of books searchable (which is arguably of greater average quality than the universe of websites) potentially has huge epistemic benefits. Even though Internet users will have to go buy the books or check them out of the library, the ability to locate books with relevant information is clearly a very valuable service. In fact, because it increases the demand for their products, it is a valuable service to authors and publishers as well as Internet users. Even so, some authors and publishers claim that making copies of entire books without the permission of the copyright holder is copyright infringement and is not protected by the fair use limitation. If they are right about this and manage to stop Google's plan, we may have to forgo the aforementioned epistemic benefits as a result of our current intellectual property policies.

\section{Conclusion}

This paper has surveyed many of the ways in which intellectual property policies can impact knowledge acquisition both positively and negatively. For example, I have looked at how intellectual property policies can affect the amount of information that people create, the quality of that information, the accessibility of that information, the diversity of that information, and even the locatability of that information. The hope is that these considerations will facilitate the evaluation of such policies.

However, the evaluation of any particular intellectual property policy will require much additional work. First, we need empirical data on exactly what the epistemic consequences of adopting that policy are likely to be. Second, we need to determine the appropriate tradeoff between different epistemic values when there is a conflict (e.g., between the number of knowledge types and the number of knowledge tokens). Finally, we need to determine the appropriate tradeoff between epistemic values and the other sorts of values that come into an ethical evaluation of information management policies.

\section{References}

Anderson, Chris. 2006. The Long Tail. New York: Hyperion.

Andrews, Lori, Jordan Paradise, Timothy Holbrook, and Danielle Bochneak. 2006. "When Patents Threaten Science." Science 314:1395-96.

Brown, Michael F. 1998. "Can Culture Be Copyrighted?" Current Anthropology 39:193222. 
Caldwell, Chris. 2007. "Illegal Primes." The Prime Glossary http://primes.utm.edu/glossary/page.php?sort=Illegal

Carlson, Scott. 2005. "Whose Work Is It, Anyway?" Chronicle of Higher Education 51(47):A33.

Dembski, William A. 2004. "The Logical Underpinnings of Intelligent Design." Pp. 31130 in Debating Design: From Darwin to DNA, eds. William A. Dembski and Michael Ruse. Cambridge: Cambridge.

Dorbolo, Jon. 1997. "Economics Epistemology." American Philosophical Association Newsletter 97(1).

Dunham, William. 1990. Journey Through Genius. New York: Wiley.

English, Larry P. 1999. Improving Data Warehouse and Business Information Quality. New York: Wiley.

Fallis, Don. 2004a. "Epistemic Value Theory and Information Ethics." Minds and Machines 14:101-17.

Fallis, Don. 2004b. "On Verifying the Accuracy of Information: Philosophical Perspectives." Library Trends 52:463-87.

Fallis, Don. 2007. "Epistemic Value Theory and the Digital Divide." Pp. 29-46 in Information Technology and Social Justice, eds. Emma Rooksby and John Weckert. Hershey, Pennsylvania: Idea Group.

Fort, Charles. 1923/1941. The Book of Charles Fort. New York: H. Holt.

Gettier, Edmund. 1963. "Is Justified True Belief Knowledge?" Analysis 23:121-23.

Goldman, Alvin I. 1999. Knowledge in a Social World. New York: Oxford.

Hettinger, Edwin C. 1989. "Justifying Intellectual Property." Philosophy and Public Affairs 18:31-52.

Hollis, Martin. 1982. "Education As a Positional Good." Journal of Philosophy of Education 16:235-44.

Hume, David. 1748/1977. An Enquiry Concerning Human Understanding. ed. Eric Steinberg. Indianapolis: Hackett.

Jefferson, Thomas. 1813/1944. "To Isaac McPherson." Pp. 629-30 in The Life and Selected Writings of Thomas Jefferson, eds. Adrienne Koch and William Peden. New York: Modern Library.

Landes, William M. and Richard A. Posner. 1989. "An Economic Analysis of Copyright Law." Journal of Legal Studies 18:325-63. 
Lessig, Lawrence. 2004. "Copyrighting the President." Wired 12(8):94.

Locke, John. 1689/1976. The Second Treatise of Government. Oxford: Basil Blackwell.

Mann, Charles C. 1998. "Who Will Own Your Next Good Idea?" Atlantic Monthly (September):57-82.

Meiklejohn, Alexander. 1981. "The First Amendment Is an Absolute." Pp. 246-61 in Alexander Meiklejohn: Teacher of Freedom, ed. Cynthia S. Brown. Berkeley: Meiklejohn Civil Liberties Institute.

Mill, John S. 1859/1978. On Liberty. ed. Elizabeth Rapaport. Indianapolis: Hackett.

Miller, Holmes. 1996. "The Multiple Dimensions of Information Quality." Information Systems Management 13:79-82.

Monmonier, Mark. 1991. How to Lie With Maps. Chicago: University of Chicago.

Moore, Adam D. 2001. Intellectual Property and Information Control. New Brunswick: Transaction Publishers.

Paine, Lynn S. 1991. "Trade Secrets and the Justification of Intellectual Property: A Comment on Hettinger." Philosophy and Public Affairs 20:247-63.

Paterson, R. W. K. 1979. "Towards an Axiology of Knowledge." Journal of Philosophy of Education 13:91-100.

Posner, Richard A. 2007. The Little Book of Plagiarism. New York: Pantheon Books.

Resnik, David B. 2006. "Openness versus Secrecy in Scientific Research." Episteme 2:135-47.

Sax, Joseph L. 2000. "Not So Public: Access to Collections." RBM 1:101-14.

Shapiro, Carl and Hal R. Varian. 1999. Information Rules. Boston: Harvard Business School.

Snapper, John W. 1999. "On the Web, Plagiarism Matters More Than Copyright Policy." Ethics and Information Technology 1:127-36.

Spinello, Richard A. 2003. "The Future of Intellectual Property." Ethics and Information Technology 5:1-16.

Stevenson, Gelvina R. 2000. "Trade Secrets: The Secret to Protecting Indigenous Ethnobiological (Medicinal) Knowledge." New York University Journal of International Law and Politics 32:1119-74.

Toobin, Jeffrey. 2007. "Google's Moon Shot." New Yorker (February 5) http://www.newyorker.com/reporting/2007-02/05/070205fa_fact_toobin. 
Vaidhyanathan, Siva. 2002. "Copyright As Cudgel." The Chronicle of Higher Education 48(47):B7.

Warner, Julian. 1993. "Writing and Literary Work in Copyright: A Binational and Historical Analysis." Journal of the American Society for Information Science 44:307-21. 